\title{
Níveis Nutricionais de Cobre para Frangos de Corte Machos e Fêmeas nas Fases de Crescimento e Terminação 1
}

\section{Marlene Schmidt ${ }^{2}$, Paulo Cezar Gomes ${ }^{3}$, Luiz Fernando Teixeira Albino ${ }^{4}$, Horacio Santiago Rostagno ${ }^{4}$, Paulo Roberto Cecon ${ }^{5}$, Edwiney Sebastião Cupertino ${ }^{6}$}

\begin{abstract}
RESUMO - Com o objetivo de determinar a exigência de cobre ( $\mathrm{Cu}$ ) para frangos de corte nas fases de crescimento (22 - 42 dias) e terminação (43 - 54 dias), dois experimentos foram conduzidos, utilizando-se 288 e 196 aves, metade machos e metade fêmeas, respectivamente. Elaboraram-se duas dietas basais, atendendo às exigências nutricionais das aves nas fases estudadas, com exceção do $\mathrm{Cu}$, que ficou deficiente em 1,40 e 1,33 ppm, respectivamente. Os tratamentos de ambos os experimentos consistiram dos níveis de suplementação de $\mathrm{Cu}$, provenientes do sulfato de $\mathrm{Cu}$, resultando em um total de 1,40;4,90; 8,40; 11,90; 15,40 e 18,90 ppm de Cu na dieta para a fase de crescimento e 1,$33 ; 4,83 ; 8,33 ; 11,83 ; 15,33$ e $18,83 \mathrm{ppm}$ de $\mathrm{Cu}$ para a fase final. As variáveis avaliadas foram: ganho de peso, consumo de ração, conversão alimentar e concentração de $\mathrm{Cu}$ no osso, no fígado e no soro. Os níveis de $\mathrm{Cu}$, em ambas as fases, não influenciaram o desempenho das aves e a concentração de $\mathrm{Cu}$ no osso, havendo, porém, efeito sobre as concentrações de Cu no fígado e no soro na fase de crescimento. Na fase de terminação, somente houve efeito dos níveis de $\mathrm{Cu}$ da dieta sobre a concentração de $\mathrm{Cu}$ no fígado. $\mathrm{Na}$ fase de crescimento, optou-se pelo valor de exigência estimado pela variável Cu no soro, que foi de 11,1 ppm. Para a fase de terminação, conclui-se que os níveis de $\mathrm{Cu}$ de 8,5 a 11 ppm, normalmente presentes em dietas à base de milho e farelo de soja, são suficientes para o adequado desenvolvimento animal.
\end{abstract}

Palavras-chave: exigência, fígado, mineral, osso, soro

\section{Copper Nutritional Levels for Male and Female Broilers in the Growing and Finishing Phases}

\begin{abstract}
Two experiments, with 288 and 196 birds, half males and half females, respectively, were carried out to determine the copper $(\mathrm{Cu})$ requirements for broilers in the growing (from 22 to 42 days) and finishing (from 43 to 54 days) phases. Two basal diets were formulated to meet the bird nutritional requirements, except for $\mathrm{Cu}$, that was deficient at the levels of $1.40 \mathrm{and} 1.33 \mathrm{ppm}$, respectively. The treatments of both experiments consisted of the $\mathrm{Cu}$ supplementation levels, from $\mathrm{Cu}$ sulfate, resulting in a total of $1.40,4.90,8.40,11.90,15.40$ and $18.90 \mathrm{ppm} \mathrm{Cu}$ in the diet for the growing of phase and 1.33, 4.83, 8.33, 11.83, 15.33 and 18.33 ppm $\mathrm{Cu}$ in the finishing phase. Average weight gain, feed intake, feed:gain ratio and $\mathrm{Cu}$ concentration in the bone, liver and serum were the evaluated variables. Copper levels, in the both phases, did not affect bird performance and $\mathrm{Cu}$ concentration in the bone. However, effect on the $\mathrm{Cu}$ concentration in the liver and serum was observed in the growing phase. In the finishing phase, $\mathrm{Cu}$ levels affected only $\mathrm{Cu}$ concentration in the liver. In the growing phase, was choosen the requirement value estimated by the variable $\mathrm{Cu}$ concentration in the serum, which was $11.1 \mathrm{ppm}$. In the finishing phase, levels of 8.5 to $11 \mathrm{ppm}$, commonly present in corn and soybean meal based diets, are adequate to animal performance.
\end{abstract}

Key Words: requirement, liver, mineral, bone, serum

\section{Introdução}

Importantes avanços nos sistemas de produção de aves vêm sendo alcançados, grande parte em função do desenvolvimento tecnológico nas áreas de genética, sanidade e nutrição, evidenciando que as exigências nutricionais precisam ser reestabelecidas.

$\mathrm{O} \mathrm{Cu}$ exerce importantes funções no organismo animal ao longo de toda sua vida. Participa na forma- ção da hemoglobolina e de numerosas metaloenzimas, incluindo a ceruloplasmina (glicoproteína transportadora de átomos de cobre no sangue e indispensável à oxidação do ferro) e a citocromo oxidase, que desempenha função importante na respiração celular.

Contudo, estudos comprovam que normalmente ocorre redução da necessidade de minerais com o avanço da idade. Vitaminas e minerais traços representam somente uma pequena fração no custo total de

\footnotetext{
${ }^{1}$ Parte da tese apresentada pela primeira autora à UFV para obtenção do título de Magister Scientiae.

2 Aluna do curso de Zootecnia - Doutourado da Universidade Federal de Viçosa - UFV - MG. Bolsista CNPq. E.mail: zooschmidt@yahoo.com.br

3 Prof. Adjunto do DZO/UFV - Viçosa - MG. Bolsista do CNPq. E.mail: pcgomes@ufv.br

4 Prof. Titular do DZO/UFV - Viçosa - MG. E.mail: lalbino@ufv.br; rostagno@ufv.br

5 Prof. Ajunto do DPI/UFV - Viçosa - MG. E.mail: cecon@dpi.ufv.br

${ }^{6}$ Aluno do curso de Zootecnia - Doutourado da Universidade Federal de Viçosa - UFV - MG. Bolsista do CNPq.
} 
produção, mas sua retirada da dieta durante 5 a 7 dias antes do abate poderia reduzir significativamente os custos de produção (Rutz et al., 1999).

A deficiência de trabalhos atualizados sobre exigência de $\mathrm{Cu}$ nas dietas práticas de aves pode estar promovendo o uso inadequado deste micromineral nas rações. Conhecer a quantidade mínima de nutrientes exigidos pelo animal é importante para seu adequado desenvolvimento, para a queda dos custos de produção e para a redução da quantidade de poluentes eliminados ao meio ambiente via dejetos oriundos da produção.

Torna-se evidente a necessidade de se estabelecer as exigências de $\mathrm{Cu}$ para frangos de corte nas fases de crescimento e terminação.

\section{Material e Métodos}

Nos experimentos das fases de crescimento (22 a 42 dias) e terminação (43 a 54 dias de idade), foram utilizados 288 e 192 frangos de corte, respectivamente, distribuídos em 48 boxes de bateria metálica. Em ambos os experimentos, adotou-se um esquema fatorial $6 \times 2$, seis níveis de $\mathrm{Cu}$ e dois sexos (macho e fêmea), em delineamento inteiramente casualizado, com quatro repetições e seis e quatro aves por unidade experimental, respectivamente.

As aves foram criadas de acordo com as recomendações de manejo descritas por Gomes et al. (1996), adotando-se o programa de luz contínuo, ou seja, 24 horas de luz (natural + artificial) durante todo o período experimental.

A composição química dos ingredientes das dietas experimentais (Tabela 1) e da água fornecida aos animais (antes e durante de cada fase experimental) foi determiada conforme metodologia descrita por Silva (1998). O sulfato de $\mathrm{Cu}\left(\mathrm{CuSO}_{5} \mathrm{H}_{2} \mathrm{O}\right)$ utilizado em ambos os experimentos continha $25 \%$ de $\mathrm{Cu}$, ao passo que a análise da água coletada antes e durante as fases experimentais não indicou presença de $\mathrm{Cu}$.

As dietas basais (fase de crescimento e terminação) foram elaboradas para atender às exigências nutricionais das aves de acordo com as recomendações de Rostagno et al. (2000), com exceção do $\mathrm{Cu}$ que permaneceu deficiente em 1,40 e $1,33 \mathrm{ppm}$, respectivamente (Tabela 2). Os tratamentos consistiram dos níveis de suplementação de $\mathrm{Cu}$, provenientes do sulfato de $\mathrm{Cu}$ comercial, resultando num total de 1,$40 ; 4,90 ; 8,40 ; 11,90 ; 15,40 \mathrm{e}$ $18,90 \mathrm{ppm}$ na dieta para a fase de crescimento e 1,$33 ; 4,83 ; 8,33 ; 11,83 ; 15,33$ e 18,83 ppm na dieta para a fase final.

As pesagens foram feitas no início e no final dos experimentos, para averiguação de ganho de peso, consumo de ração e conversão alimentar. Após o término dos experimentos, foram selecionadas, para coleta de sangue, 144 e 96 aves das fases de crescimento e terminação, respectivamente, representantes

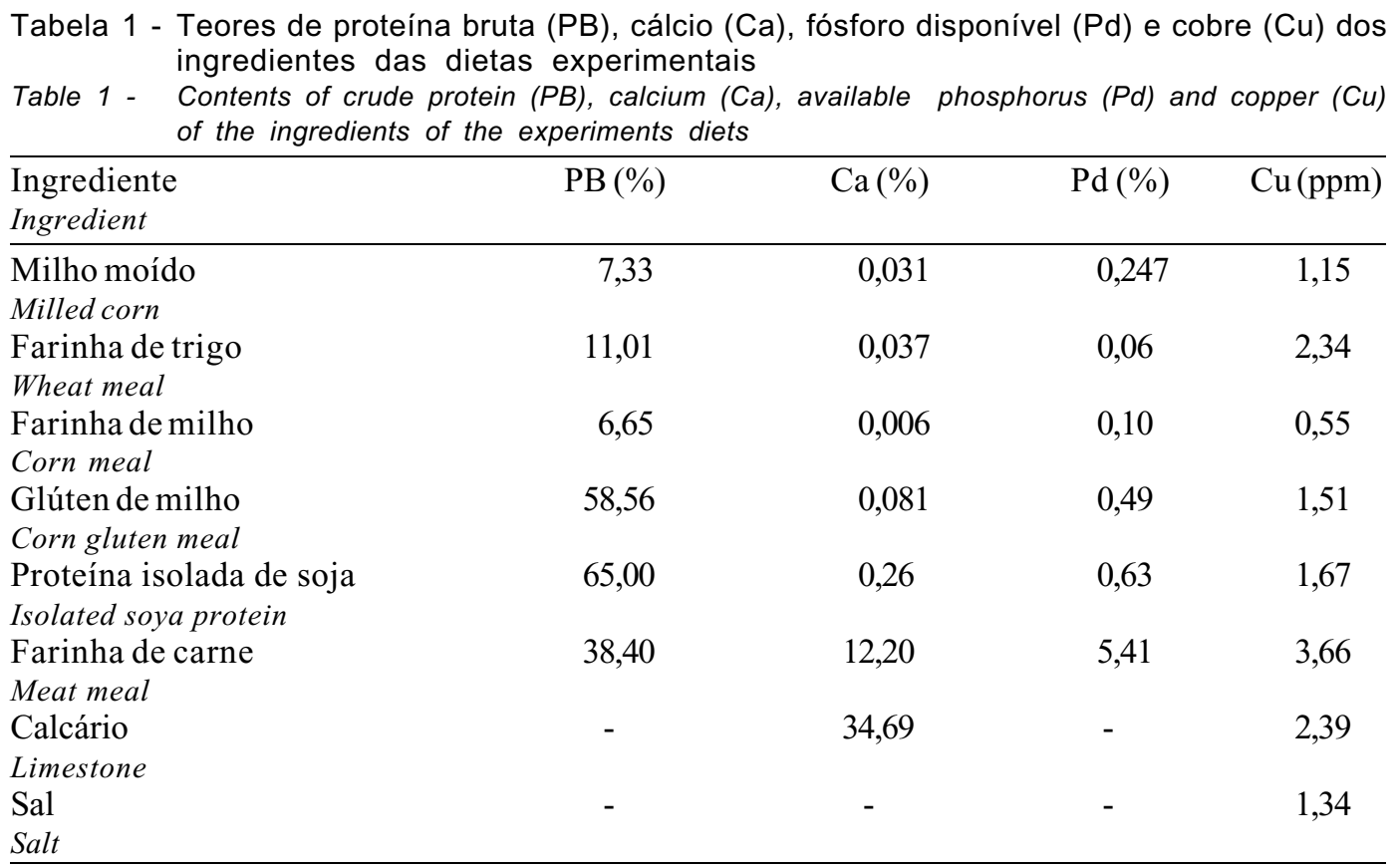

R. Bras. Zootec., v.34, n.3, p.890-899, 2005 
Tabela 2 - Composição percentual e valor nutricional da dieta basal nos períodos de crescimento (I) e terminação (II)

Table 2 - Percentage composition and nutritional value of the basal diet for the growing (I) and finishing (II) periods

\begin{tabular}{|c|c|c|}
\hline $\begin{array}{l}\text { Ingrediente } \\
\text { Ingredient }\end{array}$ & $\begin{array}{c}\text { Dieta basal I (\%) } \\
\text { Basal diet I }\end{array}$ & $\begin{array}{c}\text { Dieta basal II (\%) } \\
\text { Basal diet II }\end{array}$ \\
\hline Milho moído & 43,18 & 53,04 \\
\hline $\begin{array}{l}\text { Milled corn } \\
\text { Farinha de trigo }\end{array}$ & 13,00 & 8,00 \\
\hline $\begin{array}{l}\text { Wheat meal } \\
\text { Farinha de milho } \\
\text { Corn meal }\end{array}$ & 14,70 & 11,00 \\
\hline $\begin{array}{l}\text { Óleo de soja } \\
\text { Soybean oil }\end{array}$ & 1,15 & 1,95 \\
\hline $\begin{array}{l}\text { Glúten de milho } \\
\text { Corn gluten meal }\end{array}$ & - & 4,00 \\
\hline $\begin{array}{l}\text { Proteína isolada de soja } \\
\text { Isolated soya protein }\end{array}$ & 17,52 & 12,10 \\
\hline $\begin{array}{l}\text { Farinha de carne } \\
\text { Meat meal }\end{array}$ & 5,62 & 4,97 \\
\hline $\begin{array}{l}\text { Calcário } \\
\text { Limestone }\end{array}$ & 0,34 & 0,40 \\
\hline $\begin{array}{l}\text { Sal } \\
\text { Salt }\end{array}$ & 0,32 & 0,33 \\
\hline $\begin{array}{l}\text { Mistura vitamínica }{ }^{1} \\
\text { Vitamin premix }\end{array}$ & 0,10 & 0,10 \\
\hline $\begin{array}{l}\text { Mistura mineral }{ }^{2} \\
\text { Mineral premix }\end{array}$ & 0,10 & 0,10 \\
\hline $\begin{array}{l}\text { Antioxidante } \\
\text { Antioxidant }\end{array}$ & 0,01 & 0,01 \\
\hline $\begin{array}{l}\text { Anticoccidiano } \\
\text { Coccidiostatic }\end{array}$ & 0,05 & 0,05 \\
\hline $\begin{array}{l}\text { Promotor de crescimento } \\
\text { Growth promoter }\end{array}$ & 0,002 & 0,002 \\
\hline $\begin{array}{l}\text { DL-Metionina, } 99 \% \\
\text { DL-Methionine }\end{array}$ & 0,17 & 0,10 \\
\hline $\begin{array}{l}\text { Lisina HCL, } 78 \% \\
\text { Lysine }\end{array}$ & 0,20 & 0,30 \\
\hline $\begin{array}{l}\text { L-Triptofano, } 98 \% \\
\text { Tryptophan }\end{array}$ & - & 0,03 \\
\hline $\begin{array}{l}\text { Cloreto de colina, } 60 \% \\
\text { Choline cholorine }\end{array}$ & 0,033 & 0,03 \\
\hline $\begin{array}{l}\text { Areia lavada } \\
\text { Washed sand }\end{array}$ & 3,50 & 3,50 \\
\hline $\begin{array}{l}\text { Total } \\
\text { Total }\end{array}$ & 100,00 & 100,00 \\
\hline $\begin{array}{l}\text { Composição calculada } \\
\text { Calculated composition }\end{array}$ & & \\
\hline $\begin{array}{l}\text { Proteína bruta, \% } \\
\text { Crude protein }\end{array}$ & 19,534 & 18,074 \\
\hline $\begin{array}{l}\mathrm{EM}, \mathrm{kcal} / \mathrm{kg} \\
M E\end{array}$ & 3100,000 & 3201,000 \\
\hline $\begin{array}{l}\text { Fibra bruta, } \% \\
\text { Crude fiber }\end{array}$ & 1,262 & 1,380 \\
\hline $\begin{array}{l}\text { Ácido linoléico, \% } \\
\text { Linoleic acid }\end{array}$ & 1,663 & 2,282 \\
\hline $\begin{array}{l}\mathrm{Ca}, \% \\
\mathrm{P} \text { disponível, \% } \\
\text { Available } P\end{array}$ & $\begin{array}{l}0,874 \\
0,407\end{array}$ & $\begin{array}{l}0,800 \\
0,365\end{array}$ \\
\hline
\end{tabular}


Continuação da Tabela 2 ...

\begin{tabular}{|c|c|c|}
\hline $\mathrm{Na}, \%$ & 0,192 & 0,192 \\
\hline $\mathrm{K}, \%$ & 0,594 & 0,495 \\
\hline $\mathrm{Cu}, \mathrm{mg} / \mathrm{kg}$ & 1,40 & 1,33 \\
\hline Lisina total, $\%$ & 1,156 & 1,042 \\
\hline \multicolumn{3}{|l|}{ Total lysine } \\
\hline \multicolumn{2}{|l|}{ Total methionine } & 0,413 \\
\hline $\begin{array}{l}\text { Metionina + Cistina, } \% \\
\text { Methionine + cystine }\end{array}$ & Methionine + cystine & 0,749 \\
\hline $\begin{array}{l}\text { Treonina, } \% \\
\text { Threonine }\end{array}$ & 0,749 & 0,690 \\
\hline $\begin{array}{l}\text { Triptofano, } \% \\
\text { Tryptophan }\end{array}$ & 0,217 & 0,205 \\
\hline \multicolumn{3}{|c|}{ 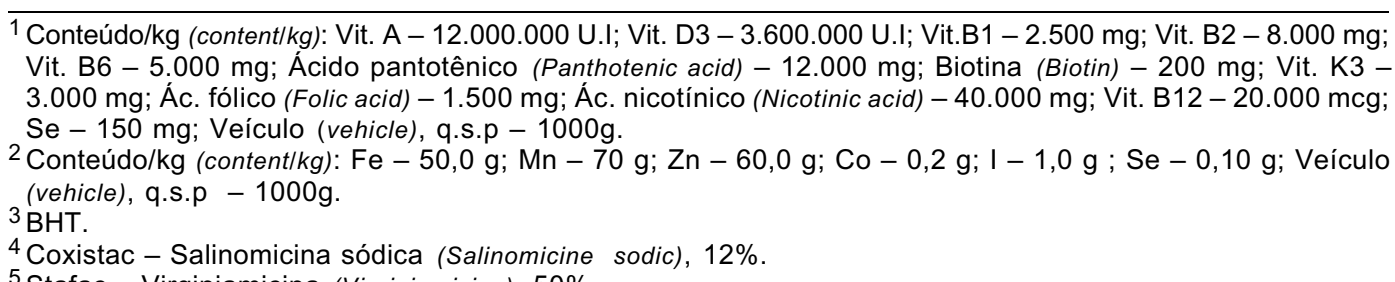 } \\
\hline
\end{tabular}

do peso médio do boxe. Posteriormente, foram abatidas para a extração do fígado e da tíbia, visando a análise da concentração de $\mathrm{Cu}$.

Para a coleta de sangue, as aves foram submetidas a jejum forçado, para proporcionar mesmo status metabólico de $\mathrm{Cu}$ no sangue. Foram mantidas em jejum por 1 hora de jejum, seguida por 1 hora de alimentação normal (para que todas as aves enchessem o papo). Em seguida, retiraram-se os comedouros, em intervalos de 5 minutos e em ordem crescente da numeração das gaiolas. Quando o comedouro da última gaiola foi retirado, iniciou-se a coleta de sangue das aves, obedecendo a mesma seqüência e mesmo intervalo. O sangue foi coletado por punção cardíaca anterior, sendo dessorado naturalmente em ambiente de temperatura controlada. $\mathrm{O}$ soro foi transferido em vidraria adequada e submetido a análise de concentração de $\mathrm{Cu}$, realizada segundo Silva (1998), em um aparelho denominado "Plasma", que fez as leituras da concentração de $\mathrm{Cu}$ no soro em ppb (partes em um bilhão). No final, os valores obtidos em ppb, foram convertidos para $\mathrm{mg} / \mathrm{L}$.

As tíbias, com as cartilagens adjacentes e livres de tecido muscular, e os fígados foram levados à estufa de ventilação forçada $\left(65^{\circ} \mathrm{C}\right)$ por 72 horas, desengordurados em extrator Soxhlet por 8 horas, triturados em moinhos de aço inoxidável, pesados em balança analítica, analisando-se, posteriormente, a concentração de $\mathrm{Cu}$ de acordo com a metodologia descrita por Silva (1998), em espectrofotômetro de absorção atômica.
As análises estatísticas dos parâmetros avaliados foram realizadas utilizando-se o programa SAEG (Sistema para Análises Estatísticas e Genéticas), desenvolvido pela Universidade Federal de Viçosa - UFV (1997), e as estimativas de exigência de $\mathrm{Cu}$ foram feitas adotando-se os modelos Quadrático e Linear e "Linear Response Plateau" (LRP), conforme o ajustamento dos dados obtidos para cada variável.

\section{Resultados e Discussão}

Durante a fase experimental, não foram observadas anormalidades no desenvolvimento de pernas, com raras e aleatórias incidências de anormalidades ósseas, não atribuídas a efeitos de tratamento. Estes resultados estão de acordo com os reportados por Rucker et al. (1975), que também não observaram problemas de pernas ou fragilidades ósseas em frangos alimentados com dieta contendo mais de 1 ppm de $\mathrm{Cu}$.

Os resultados de desempenho de frangos de corte no período de 22 a 42 dias de idade encontram-se na tabela 3 . Não se verificou interação entre sexo e níveis de $\mathrm{Cu}$ $(\mathrm{P}>0,05)$, comprovando que estes fatores agem de forma independente sobre as variáveis de desempenho.

Não houve efeito significativo dos níveis de $\mathrm{Cu}$ $(\mathrm{P}>0,05)$ sobre o ganho de peso, o consumo de ração e a conversão alimentar, o que está de acordo com os relatos de Bertechini et al. (1993) e Cachoni (1993), que, ao trabalharem com níveis de 8,5 a $300 \mathrm{ppm}$ de $\mathrm{Cu}$, não observaram resposta no desempenho das aves. 
Tabela 3 - Desempenho de frangos de corte machos $(M)$ e fêmeas $(F)$ de 22 a 42 dias de idade, submetidos a diferentes níveis de cobre $(\mathrm{Cu})$

Table 3 - Performance of male $(M)$ and female $(F)$ broilers submitted to different copper $(\mathrm{Cu})$ levels from 22 to 42 days of age

\begin{tabular}{|c|c|c|c|c|}
\hline $\begin{array}{l}\text { Nível de } \mathrm{Cu} \\
(\mathrm{ppm}) \\
\text { Level of } \mathrm{Cu}\end{array}$ & $\begin{array}{c}\text { Sexo } \\
\text { Sex }\end{array}$ & $\begin{array}{l}\text { Ganho de peso }(\mathrm{g}) \\
\text { Body weight gain }\end{array}$ & $\begin{array}{l}\text { Consumo de } \\
\text { ração }(\mathrm{g}) \\
\text { Feed intake }\end{array}$ & $\begin{array}{c}\text { Conversão alimentar }(g: g) \\
\text { Feed:gain ratio }\end{array}$ \\
\hline 1,40 & M & 1306,8 & 2341,3 & 1,79 \\
\hline 4,90 & M & 1293,0 & 2344,8 & 1,81 \\
\hline 8,40 & M & 1269,5 & 2318,8 & 1,83 \\
\hline 11,90 & M & 1268,8 & 2337,8 & 1,84 \\
\hline 15,40 & M & 1329,0 & 2386,0 & 1,80 \\
\hline \multirow[t]{3}{*}{18,90} & M & 1280,0 & 2364,0 & 1,83 \\
\hline & Média & $1291,2 \mathrm{a}$ & $2348,9 a$ & $1,82 \mathrm{a}$ \\
\hline & Mean & & & \\
\hline 1,40 & $\mathrm{~F}$ & 1186,5 & 2166,3 & 1,83 \\
\hline 4,90 & $\mathrm{~F}$ & 1166,0 & 2149,0 & 1,85 \\
\hline 8,40 & $\mathrm{~F}$ & 1207,0 & 2159,0 & 1,79 \\
\hline 11,90 & $\mathrm{~F}$ & 1163,5 & 2185,0 & 1,88 \\
\hline 15,40 & $\mathrm{~F}$ & 1215,8 & 2238,0 & 1,84 \\
\hline \multirow[t]{2}{*}{18,90} & $\mathrm{~F}$ & 1160,5 & 2130,0 & 1,84 \\
\hline & $\begin{array}{l}\text { Média } \\
\text { Mean }\end{array}$ & $1183,2 \mathrm{~b}$ & $2171,2 \mathrm{~b}$ & $1,84 \mathrm{a}$ \\
\hline \multicolumn{2}{|c|}{ Níveis de $\mathrm{Cu}$ (Levels of $\mathrm{Cu}$ ) } & Ns & $\mathrm{ns}$ & $\mathrm{ns}$ \\
\hline \multicolumn{2}{|c|}{$\operatorname{Sexo}(\operatorname{Sex})$} & $* *$ & $* *$ & $\mathrm{~ns}$ \\
\hline \multicolumn{2}{|c|}{ Sexo x Níveis (Sex $x$ Levels) } & Ns & $\mathrm{ns}$ & $\mathrm{ns}$ \\
\hline \multicolumn{2}{|l|}{ CV $(\%)$} & 3,58 & 3,12 & 2,85 \\
\hline
\end{tabular}

Médias seguidas pela mesma letra na coluna não diferem entre si a $5 \%$ pelo teste $\mathrm{F}$ (Averages followed by the same letter in the column do not differ at level of $5 \%$ by $F$ test). $\mathrm{CV}$ - Coeficiente de variação (Coefficient of variation). ${ }^{* *}(P<0,01)$; ns $(P>0,05)$ pelo teste $F($ by $F$ test).

Houve efeito de sexo $(\mathrm{P}<0,01)$ sobre o consumo de ração e o ganho de peso, de modo que os machos consumiram $8,18 \%$ a mais que as fêmeas e ganharam $9,13 \%$ a mais de peso.

Os resultados da concentração de $\mathrm{Cu}$ no osso, no fígado e no soro estão apresentados na tabela 4. Não houve interação entre sexo e níveis de $\mathrm{Cu}(\mathrm{P}>0,05)$, demonstrando que estes fatores atuam de forma independente sobre estes parâmetros. Não se observou efeito de sexo $(\mathrm{P}>0,05)$ sobre a concentração de $\mathrm{Cu}$ no osso, no fígado e no soro.

Não houve efeito significativo $(\mathrm{P}>0,05)$ dos níveis de $\mathrm{Cu}$ sobre a concentração de $\mathrm{Cu}$ no osso, demonstrando que o $\mathrm{Cu}$, dentro dos níveis estudados, não interferiu na concentração de $\mathrm{Cu}$ nos ossos, justificando a nãoconstatação de anormalidades ósseas. Trabalhando com níveis superiores (8,5 à 300 ppm de Cu), Bertechini et al. (1993) e Cachoni (1993) também não encontraram diferença significativa da concentração de $\mathrm{Cu}$ na tíbia, concluindo que este não é um bom parâmetro para medir a exigência e biodisponibilidade de $\mathrm{Cu}$, uma vez que não é influenciado pelo aporte da dieta.
Houve efeito $(\mathrm{P}<0,01)$ dos níveis de $\mathrm{Cu}$ da dieta sobre a concentração de $\mathrm{Cu}$ no fígado, o que está de acordo com os estudos de Bertechini et al. (1993), Aoyagy \& Baker (1993), Ledoux et al. (1991), Zanetti et al. (1991), Cachoni (1993) e Ewing et al. (1998), que também observaram acúmulo de $\mathrm{Cu}$ no fígado de aves quando estas receberam dietas com níveis crescentes deste elemento.

Observou-se efeito significativo $(\mathrm{P}<0,05)$ dos níveis de $\mathrm{Cu}$ sobre o teor de $\mathrm{Cu}$ no soro. Bertechini et al. (1993), Zanetti et al. (1991) e Cachoni (1993) também observaram, em frangos de corte, que a concentração de $\mathrm{Cu}$ no soro respondia à suplementação de $\mathrm{Cu}$ da dieta.

As estimativas de exigência de $\mathrm{Cu}$ estão apresentadas na tabela 5. Como não houve interação $(\mathrm{P}>0,05)$ entre sexo e níveis de $\mathrm{Cu}$, as equações foram ajustadas para ambos os sexos.

Os valores de exigência de $\mathrm{Cu}$ pelas aves foram de $18,90 \mathrm{ppm}$ para a concentração de $\mathrm{Cu}$ no fígado, mediante o modelo linear, e de 11,10 ppm para a concentração de $\mathrm{Cu}$ no soro, pelo modelo quadrático. 
Tabela 4 - Efeito dos diferentes níveis de cobre $(\mathrm{Cu})$ da ração sobre a concentração de Cu no osso (CuO), no fígado (CuF) e no soro (CuS) de frangos de corte machos (M) e fêmeas $(F)$, de 22 a 42 dias de idade

Table 4 - Effect of different dietary copper (Cu) levels on Cu concentration in the bone (CuO), in the liver (CuF) and in the serum (CuS) of male (M) and female (F) broilers from 22 to 42 days of age

\begin{tabular}{|c|c|c|c|c|}
\hline $\begin{array}{l}\text { Nível de } \mathrm{Cu}(\mathrm{ppm}) \\
\text { Level of } \mathrm{Cu}\end{array}$ & $\begin{array}{l}\text { Sexo } \\
\text { Sex }\end{array}$ & $\mathrm{CuO}(\mathrm{ppm})$ & $\mathrm{CuF}(\mathrm{ppm})$ & $\mathrm{CuS}(\mathrm{mg} / \mathrm{L})$ \\
\hline 1,40 & M & 5,03 & 10,90 & 0,126 \\
\hline 4,90 & M & 5,08 & 12,99 & 0,128 \\
\hline 8,40 & M & 5,19 & 13,92 & 0,135 \\
\hline 11,90 & M & 5,22 & 13,94 & 0,130 \\
\hline 15,40 & M & 5,13 & 14,74 & 0,128 \\
\hline \multirow[t]{2}{*}{18,90} & $\mathrm{M}$ & 5,17 & 16,32 & 0,129 \\
\hline & $\begin{array}{l}\text { Média } \\
\text { Mean }\end{array}$ & $5,14 \mathrm{a}$ & $13,80 \mathrm{a}$ & $0,129 \mathrm{a}$ \\
\hline 1,40 & F & 5,04 & 11,05 & 0,126 \\
\hline 4,90 & $\mathrm{~F}$ & 5,05 & 12,61 & 0,127 \\
\hline 8,40 & $\mathrm{~F}$ & 5,20 & 13,49 & 0,136 \\
\hline 11,90 & $\mathrm{~F}$ & 5,24 & 14,12 & 0,130 \\
\hline 15,40 & $\mathrm{~F}$ & 5,15 & 14,73 & 0,130 \\
\hline \multirow[t]{2}{*}{18,90} & F & 5,14 & 16,80 & 0,129 \\
\hline & $\begin{array}{l}\text { Média } \\
\text { Mean }\end{array}$ & $5,14 \mathrm{a}$ & $13,80 \mathrm{a}$ & $0,130 \mathrm{a}$ \\
\hline Níveis de $\mathrm{Cu}$ & $\mathrm{ns}$ & $* * 1$ & $* 2$ & \\
\hline \multicolumn{5}{|l|}{ Levels of $\mathrm{Cu}$} \\
\hline Sexo & $\mathrm{ns}$ & $\mathrm{ns}$ & $\mathrm{ns}$ & \\
\hline \multicolumn{5}{|l|}{$\operatorname{Sex}$} \\
\hline Sexo x Níveis & $\mathrm{ns}$ & $\mathrm{ns}$ & $\mathrm{ns}$ & \\
\hline \multicolumn{5}{|l|}{ Sex $x$ Levels } \\
\hline CV (\%) & 3,84 & 5,03 & 4,49 & \\
\hline
\end{tabular}

Tabela 5 - Sumário das análises para determinação das exigências de cobre $(\mathrm{Cu})$ estimadas pelos modelos linear e quadrático, para frangos de corte de 22 a 42 dias de idade

Table 5 - Summary of the determination analyses of copper $(\mathrm{Cu})$ requeriment estimated by linear and quadratic models, for broilers from 22 to 421 days of age

\begin{tabular}{|c|c|c|c|c|}
\hline \multicolumn{5}{|c|}{$\begin{array}{c}\text { Modelos quadrático e linear } \\
\text { Quadratic and linear models }\end{array}$} \\
\hline $\begin{array}{l}\text { Variável } \\
\text { Variable }\end{array}$ & $\begin{array}{l}\text { Equação ajustada } \\
\text { Fitted equation }\end{array}$ & Ex. & $r^{2}$ & SQD \\
\hline $\mathrm{CuF}(\mathrm{ppm})$ & $\hat{Y}=10,9771+0,278082 \mathrm{~N}$ & $\geq 18,90$ & $0,95 * *$ & 1 \\
\hline $\mathrm{CuS}(\mathrm{mg} / \mathrm{L})$ & $\hat{Y}=0,124207+0,00131914 \mathrm{~N}-0,0000594029 \mathrm{~N}^{2}$ & 11,10 & $0,45^{*}$ & $29 \times 10^{-5}$ \\
\hline
\end{tabular}


A variável $\mathrm{Cu}$ no fígado indicou que os níveis estudados não foram suficientes para atingir o requerimento nutricional de $\mathrm{Cu}$ para frangos de corte na fase de crescimento, sugerindo o maior nível como exigência. Contudo, o fígado não é um bom parâmetro para medir a exigência de minerais por ser um órgão que vai acumulando o excesso à medida que se aumenta os níveis de suplementação (Zanetti et al., 1991; Cachoni, 1993). Portanto, optou-se pela utilização do valor de exigência encontrado pela variável $\mathrm{Cu}$ no soro.

Comportamento semelhante para concentração de $\mathrm{Cu}$ no soro de aves foi obtido por Aoyagy e Baker (1993), que, embora não tenham trabalhado com frangos de corte na fase de crescimento, observaram biologicamente um comportamento quadrático do teor de $\mathrm{Cu}$ no soro das aves alimentadas com níveis crescentes de $\mathrm{Cu}$ ao final dos 23 dias de idade.

Em se tratando de animais sadios, a variável $\mathrm{Cu}$ no soro é viável para avaliar o status nutricional de $\mathrm{Cu}$ no organismo animal (Mills, 1987). Portanto, nas condições em que o experimento foi conduzido, conclui-se que a exigência de $\mathrm{Cu}$ para frangos de corte, machos e fêmeas, de 22 a 42 dias de idade é de 11,10 ppm, ressaltando-se que dietas práticas para frangos de corte, à base de milho e farelo de soja, já contém normalmente de 8,5 a 11,1 ppm de $\mathrm{Cu}$ e que a biodisponibilidade de $\mathrm{Cu}$ no farelo de soja é de $38 \%$.

modelo linear, e de 11,10 ppm para a concentração de $\mathrm{Cu}$ no soro, pelo modelo quadrático.

A variável $\mathrm{Cu}$ no fígado indicou que os níveis estudados não foram suficientes para atingir o requerimento nutricional de $\mathrm{Cu}$ para frangos de corte na fase de crescimento, sugerindo o maior nível como exigência. Contudo, o fígado não é um bom parâmetro para medir a exigência de minerais por ser um órgão que vai acumulando o excesso à medida que se aumenta os níveis de suplementação (Zanetti et al., 1991; Cachoni, 1993). Portanto, optou-se pela utilização do valor de exigência encontrado pela variável $\mathrm{Cu}$ no soro.

Comportamento semelhante para concentração de $\mathrm{Cu}$ no soro de aves foi obtido por Aoyagy e Baker (1993), que, embora não tenham níveis crescentes de $\mathrm{Cu}$ ao final dos 23 dias de idade.

Em se tratando de animais sadios, a variável $\mathrm{Cu}$ no soro é viável para avaliar o status nutricional de $\mathrm{Cu}$ no organismo animal (Mills, 1987). Portanto, nas condições em que o experimento foi conduzido, conclui-se que a exigência de $\mathrm{Cu}$ para frangos de corte, machos e fêmeas, de 22 a 42 dias de idade é de 11,10 ppm, ressaltando-se que dietas práticas para frangos de corte, à base de milho e farelo de soja, já contém normalmente de 8,5 a $11,1 \mathrm{ppm}$ de $\mathrm{Cu}$ e que a biodisponibilidade de $\mathrm{Cu}$ no farelo de soja é de $38 \%$.

Os resultados de desempenho de frangos de corte no período de 43 a 54 dias de idade estão apresentados na tabela 6. Não houve interação entre sexo e níveis de $\mathrm{Cu}(\mathrm{P}>0,05)$, mostrando que estes fatores agem de forma independente sobre as variáveis de desempenho.

Observou-se efeito de sexo $(\mathrm{P}<0,01)$ sobre consumo de ração e ganho de peso, sendo que os machos consumiram $13,47 \%$ a mais que as fêmeas e ganharam $17,86 \%$ a mais de peso. No entanto, não se observou efeito de sexo $(\mathrm{P}>0,05)$ sobre a conversão alimentar.

Não houve efeito significativo dos níveis de $\mathrm{Cu}$ $(\mathrm{P}>0,05)$ sobre o ganho de peso, o consumo de ração e a conversão alimentar. Zanetti et al. (1991), Bertechini et al. (1993), Cachoni (1993) e Koh et al. (1996) também não observaram efeito dos níveis de $\mathrm{Cu}$ sobre as variáveis de desempenho em experimentos com frangos de corte.

Os resultados de concentração de $\mathrm{Cu}$ no osso, no fígado e no soro estão apresentados na Tabela 7. Não houve interação entre sexo e níveis de $\mathrm{Cu}(\mathrm{P}>0,05)$, revelando que estes fatores atuam de forma independente sobre estes parâmetros.

Observou-se efeito significativo $(\mathrm{P}<0,01)$ dos níveis de $\mathrm{Cu}$ sobre a concentração de $\mathrm{Cu}$ no fígado. Bertechini et al. (1993), Aoyagy \& Baker (1993), Ledoux et al. (1991), Zanetti et al. (1991), Cachoni (1993) e Ewing et al. (1998) também observaram em aves o acúmulo de $\mathrm{Cu}$ no fígado quando estas receberam dietas com níveis crescentes deste mineral.

Não se constatou efeito $(\mathrm{P}>0,05)$ dos níveis de $\mathrm{Cu}$ sobre sua concentração no osso, demonstrando que, dentro dos níveis estudados, não interferiu na concentração de $\mathrm{Cu}$ nos ossos, justificando a nãoconstatação de anormalidades ósseas. Bertechini et al. (1993) e Cachoni (1993), trabalhando com níveis superiores ( 8,5 a 300 ppm de $\mathrm{Cu}$ ), também não encontraram diferença significativa da concentração de $\mathrm{Cu}$ na tíbia e concluíram que este não é um bom parâmetro para medir a exigência ou biodisponibilidade de $\mathrm{Cu}$, uma vez que não é influenciado pelo aporte da dieta. Também não observou-se efeito $(\mathrm{P}>0,05)$ dos níveis de $\mathrm{Cu}$ em relação ao $\mathrm{Cu}$ no soro.

Não se observou efeito de sexo $(\mathrm{P}>0,05)$ sobre a concentração de $\mathrm{Cu}$ no fígado, no osso e no soro. Underwood (1977) explica que dificilmente se observa efeito de sexo sobre a concentração de $\mathrm{Cu}$ no 
Tabela 6 - Desempenho de frangos de corte machos (M) e fêmeas (F) de 43 a 54 dias de idade, submetidos a diferentes níveis de cobre $(\mathrm{Cu})$

Table 6 - Performance of male $(M)$ and female $(F)$ broilers submitted to different copper $(\mathrm{Cu})$ levels from 43 to 54 days of age

\begin{tabular}{|c|c|c|c|c|}
\hline $\begin{array}{l}\text { Nível de } \mathrm{Cu} \\
(\mathrm{ppm}) \\
\text { Level of } \mathrm{Cu}\end{array}$ & $\begin{array}{l}\text { Sexo } \\
\text { Sex }\end{array}$ & $\begin{array}{c}\text { Ganho de peso }(\mathrm{g}) \\
\text { Body weight gain }\end{array}$ & $\begin{array}{l}\text { Consumo de } \\
\text { ração }(\mathrm{g}) \\
\text { Feed intake }\end{array}$ & $\begin{array}{c}\text { Conversão alimentar }(\mathrm{g}: \mathrm{g}) \\
\text { Feed:gain ratio }\end{array}$ \\
\hline 1,33 & M & 615,0 & 1655,0 & 2,71 \\
\hline 4,83 & M & 683,3 & 1695,8 & 2,48 \\
\hline 8,33 & M & 615,3 & 1611,8 & 2,64 \\
\hline 11,83 & M & 618,0 & 1653,3 & 2,69 \\
\hline 15,33 & M & 622,3 & 1608,5 & 2,59 \\
\hline 18,83 & M & 623,0 & 1614,5 & 2,60 \\
\hline & Média & $629,5 \mathrm{a}$ & $1639,8 \mathrm{a}$ & $2,62 \mathrm{a}$ \\
\hline & Mean & & & \\
\hline 1,33 & $\mathrm{~F}$ & 549,3 & 1452,8 & 2,67 \\
\hline 4,83 & $\mathrm{~F}$ & 549,0 & 1465,0 & 2,68 \\
\hline 8,33 & $\mathrm{~F}$ & 519,0 & 1381,3 & 2,67 \\
\hline 11,83 & $\mathrm{~F}$ & 509,8 & 1396,8 & 2,76 \\
\hline 15,33 & F & 541,5 & 1455,5 & 2,70 \\
\hline 18,83 & $\mathrm{~F}$ & 536,0 & 1519,0 & 2,86 \\
\hline & Média & $534,1 \mathrm{~b}$ & $1445,1 \mathrm{~b}$ & $2,72 \mathrm{a}$ \\
\hline & Mean & & & \\
\hline Níveis de $\mathrm{Cl}$ & els of $\mathrm{Cu}$ ) & $\mathrm{ns}$ & $\mathrm{ns}$ & $\mathrm{ns}$ \\
\hline Sexo (Sex) & & $* *$ & $* *$ & $\mathrm{~ns}$ \\
\hline Sexo x Níve & (x Levels) & $\mathrm{ns}$ & $\mathrm{ns}$ & $\mathrm{ns}$ \\
\hline CV $(\%)$ & & 10,46 & 6,33 & 7,17 \\
\hline
\end{tabular}

Médias seguidas pela mesma letra na coluna não diferem entre si a $5 \%$ pelo teste $\mathrm{F}$ (Averages followed by the same letter in the column do not differ at level of $5 \%$ by $F$ test).

$\mathrm{CV}$ - Coeficiente de variação (Coefficient of variation).

** $(\mathrm{P}<0,01)$; ns $(\mathrm{P}>0,05)$, pelo teste $\mathrm{F}$ (by $\mathrm{F}$ test).

Tabela 7 - Efeito dos diferentes níveis de cobre $(\mathrm{Cu})$ da ração sobre a concentração de Cu no osso ( $\mathrm{CuO}$ ), no fígado (CuF) e no soro (CuS) de frangos de corte machos (M) e fêmeas $(F)$ de 43 a 54 dias de idade

Table 7 - Effect of different dietary copper (Cu) levels on $\mathrm{Cu}$ concentration in the bone (CuO), in the liver (CuF) and in the serum (CuS) of male (M) and female (F) broilers from 43 to 54 days of age

\begin{tabular}{|c|c|c|c|c|}
\hline $\begin{array}{l}\text { Nível de } \mathrm{Cu}(\mathrm{ppm}) \\
\text { Level of } \mathrm{Cu}\end{array}$ & $\begin{array}{l}\text { Sexo } \\
\text { Sex }\end{array}$ & $\mathrm{CuO}(\mathrm{ppm})$ & $\mathrm{CuF}(\mathrm{ppm})$ & $\mathrm{CuS}(\mathrm{mg} / \mathrm{L})$ \\
\hline 1,33 & $\mathrm{M}$ & 4,17 & 9,44 & 0,132 \\
\hline 4.83 & $\mathrm{M}$ & 4,06 & 11.35 & 0,132 \\
\hline 8,33 & M & 4,09 & 17,30 & 0,132 \\
\hline 11,83 & M & 4,13 & 19,80 & 0,131 \\
\hline 15,33 & M & 4,01 & 20,67 & 0,132 \\
\hline \multirow[t]{3}{*}{18,83} & M & 4,18 & 21,09 & 0,132 \\
\hline & Média & $4,11 \mathrm{a}$ & $16,61 \mathrm{a}$ & $0,132 \mathrm{a}$ \\
\hline & Mean & & & \\
\hline 1,33 & $\mathrm{~F}$ & 4,03 & 10,01 & 0,133 \\
\hline 4,83 & $\mathrm{~F}$ & 4,06 & 12,11 & 0,132 \\
\hline 8,33 & $\mathrm{~F}$ & 4,08 & 17,70 & 0,131 \\
\hline 11,83 & $\mathrm{~F}$ & 4,15 & 20,63 & 0,131 \\
\hline 15,33 & $\mathrm{~F}$ & 4,17 & 20,95 & 0,132 \\
\hline \multirow[t]{3}{*}{18,83} & $\mathrm{~F}$ & 4,21 & 21,85 & 0,133 \\
\hline & Média & $4,12 \mathrm{a}$ & $17,21 \mathrm{a}$ & $0,132 \mathrm{a}$ \\
\hline & Mean & & & \\
\hline Níveis de $\mathrm{Cu}$ (Levels of $\mathrm{Cu}$ ) & $\mathrm{ns}$ & $* * 1$ & $\mathrm{~ns}$ & \\
\hline $\operatorname{Sexo}(\operatorname{Sex})$ & $\mathrm{ns}$ & $\mathrm{ns}$ & $\mathrm{ns}$ & \\
\hline Sexo x Níveis (Sex $x$ Levels) & $\mathrm{ns}$ & $\mathrm{ns}$ & $\mathrm{ns}$ & \\
\hline CV $(\%)$ & 4,46 & 5,08 & 4,49 & \\
\hline
\end{tabular}

Médias seguidas pela mesma letra na coluna não diferem entre si a $5 \%$ pelo teste $\mathrm{F}$ (Averages followed by the same letter in the column do not differ at level of $5 \%$ by $F$ test).

** $(\mathrm{P}<0,01)$; ns $(\mathrm{P}>0,05)$, pelo teste $\mathrm{F}$ (by $F$ test).

CV- Coeficiente de variação (Coefficient of variation).

1 Efeito linear e Linear Response Plateau (LRP) (Linear and Linear Response Plateau effect). 
Tabela 8 - Sumário das análises para determinação das exigências de cobre (Cu), estimadas pelos modelos linear e quadrático, para frangos de corte de 22 a 42 dias de idade

Table 8 - Summary of the determination analysis of copper $(\mathrm{Cu})$ requeriment estimated by linear and quadratic models of broilers from 22 to 421 days of age

\begin{tabular}{|c|c|c|c|c|c|}
\hline \multicolumn{6}{|c|}{$\begin{array}{l}\text { Modelos quadrático e linear } \\
\text { Quadratic and linear models }\end{array}$} \\
\hline Variável & Equações ajustadas & & Ex. & $r^{2}$ & SQD \\
\hline Variable & Fitted equations & & & & \\
\hline$\overline{\mathrm{CuF}(\mathrm{ppm})}$ & $\hat{Y}=9,58686+0,724745 \mathrm{~N}$ & & $\geq 18,83$ & $0,90 * *$ & 13,5 \\
\hline & Linear Response Plateou (LRP) & & & & \\
\hline Variável & Equação da reta & Platô & Ex. & $\mathrm{r}^{2}$ & SQD \\
\hline Variable & Equations fittings & Plateau & & & \\
\hline $\mathrm{CuF}(\mathrm{ppm})$ & $\hat{Y}=7,7822+1,0618 \mathrm{~N}$ & $\hat{Y}=21,14$ & 12,58 & $0,97 * *$ & 2,31 \\
\hline
\end{tabular}

** $(\mathrm{P}<0,01) ;{ }^{*}(\mathrm{P}<0,05)$ pelo teste $\mathrm{F}$ (by $F$ test).

Ex - Exigência de cobre (copper requirement).

SQD - Soma de quadrado dos desvios (Square sum of the deviations).

CuF - Cobre no fígado (Copper in the liver).

CuS - Cobre no soro (Copper in the serum).

fígado, exceto no salmão australiano, espécie em que a fêmea possui níveis maiores que o macho.

As estimativas de exigência de $\mathrm{Cu}$ para frangos de corte no período de estão apresentadas na Tabela 8. Como não houve interação $(\mathrm{P}>0,05)$ sexo $\mathrm{x}$ níveis de $\mathrm{Cu}$, as equações foram ajustadas para ambos os sexos.

Os valores de exigência de $\mathrm{Cu}$ pelas aves para a concentração de $\mathrm{Cu}$ no fígado foram de $18,83 \mathrm{ppm}$, quando empregado o modelo linear, e de $12,58 \mathrm{ppm}$, quando empregado o modelo Linear Response Plateau (LRP).

Contudo, considerando-se que o fígado não é um bom parâmetro para medir a exigência de minerais, por acumular o excesso fornecido na dieta (Aoyagy \& Baker, 1993), e que não houve efeito dos níveis de $\mathrm{Cu}$ no soro (variável que melhor indica a exigência de $\mathrm{Cu}$ pelo animal) e sobre as variáveis de maior interesse econômico (ganho de peso, consumo de ração e conversão alimentar), sugere-se que os níveis de $\mathrm{Cu}$ de 8,5 a $11,1 \mathrm{ppm}$, normalmente presentes em dietas práticas à base de milho e farelo de soja, são suficientes para o adequado desenvolvimento animal, não havendo necessidade de suplementação desse mineral para frangos de corte machos e fêmeas de 43 a 54 dias de idade.

Este resultado está de acordo com o citado na revisão de Rutz et al. (1999), ou seja, que frangos de corte na fase de terminação, alimentados com pelo menos $5 \%$ de proteína animal, sob condições ambientais favoráveis e livres de doenças, não necessitam de suplementação mineral.

\section{Conclusões}

A exigência de $\mathrm{Cu}$ determinada para frangos de corte machos e fêmeas de 22 a 42 dias de idade foi de 11,10 ppm. Os níveis de $\mathrm{Cu}$ de 8,5 a 11,1 ppm, normalmente presentes em dietas à base de milho $\mathrm{e}$ farelo de soja, são suficientes para o adequado desenvolvimento animal, não havendo necessidade de suplementação desse mineral para frangos de corte machos e fêmeas de 43 a 54 dias de idade.

\section{Literatura Citada}

AOYAGI, S.; BAKER, D.H. Biovailability of cooper in analyticalgrade and feed-grade inorganic cooper sources when fed to provide cooper at levels below the chick's requeriment. Poultry Science, v.72, p.1075-1083, 1993.

BERTCHINI, A.G.; HOSSAIN, S.M.; MELHO, B.M. et al. Níveis nutricionais de cobre para frangos de corte na fase inicial. In. CONFERËNCIA APINCO DE CIËNCIA E TECNOLOGIA AVÍCOLAS, Santos. Anais... Campinas: Fundação de Apinco de Ciência e Tecnologia, 1993. p.2.

CACHONI, C.C. Biodisponibilidade de cobre de várias fontes comerciais para frangos de corte na fase inicial. Lavras: Universidade Federal de Lavras, 1993. 71p. Dissertação (Mestrado em Zootecnia) - Universidade Federal de Lavras, 1993.

EWING, H.P.; PESTI, G.M.; BAKALLI, R.I. et al. Studies on the feeding of cupric sulfate pentahydrate, cupric citrate, citrate, and copper oxychloride to broiler chickens. Poultry Science, v.77, p.445-448, 1998.

GOMES, P.C.; ALBINO, L.F.T.; SILVA, M.A. Criação de frangos de corte. Viçosa, MG: Universidade Federal de Viçosa, 1996. 18p. 
KOH, T.S.; PENG, R.K.; KLASING, K.C. Dietary cooper levelaffects copper metabolism during lipopolysaccharideinduced immunological stress in chicks. Poultry Science, v.75, p.867-872, 1996

LEDOUX, D.R.; HENRY, P.R.; AMMERMAN, C.B. et al. Estimation of the relative bioavailability of inorganic copper sources for chicks using tissue uptake of copper. Journal of Animal Science, v.69, p.215-222, 1991.

MILLS, C.F. Biochemical and physiological indicators of mineral status in animals: copper, cobalt and zinc. Journal of Animal Science, v.65, p.1702-1711, 1987.

ROSTAGNO, R.S.; ALBINO, L.F.T.; DONZELE, J.L. et al. Tabelas brasileiras para aves e suínos - composição de alimentos e exigências nutricionais. Viçosa, MG: Universidade Federal de Viçosa, 2000. p.140.

RUCKER, R.B.; RIGGINS, R.S.; LAUGHLIN, R. et al. Effects of nutritional copper deficiency on the biomechanical properties of bone and arterial elastin metabolism in the chicks. Journal of Nutrition, v.105, p.1062-1070, 1975.

RUTZ, F.; XAVIER, E.G.; DADALT, G.M. Exigências nutricionais para a fase final (energia, aminoácidos, vitaminas, minerais e aditivos). In. CONFERËNCIA APINCO DE CIËNCIA E TECNOLOGIA AVÍCOLAS, Santos. Anais... Campinas. FACTA, 1999. p.32-36.
SILVA, D.J. Análise de alimentos (métodos químicos e biológicos) 2.ed. Viçosa, MG: Universidade Federal de Viçosa, 1998. 165p.

UNDERWOOD, E.J. Trace elements in human an animal nutrition. 4.ed. New York: Academic Press, 1977. 545p.

UNIVERSIDADE FEDERAL DE VIÇOSA - UFV. Central de Processamento de Dados - UFV/CPD. SAEG - Sistema para análise estatística e genética. Versão 7.0 Viçosa, $M G$ : UFV, 1997. 54p.

ZANETTI, M.A.; HENRY, P.R.; AMMRMAN, C.B. et al. Estimation of the bioavailability of copper sources in chickes fed on conventional dietary amounts. British Poultry Science, v.32, p.585-588, 1991.

Recebido em: 20/10/03

Aceito em: 25/08/04 